\title{
Seroprevalence of Chronic Viral Hepatitis B in School Children Aged Less Than 10 Years in the Region of Southern Cameroon
}

\author{
Noah Noah Dominique ${ }^{1, ~ *}$, Eloumou Servais Albert Fiacre ${ }^{1,2}$, Nsenga Djapa Guy Roger ${ }^{1,4}$, \\ Ze Meka Louis Philippe ${ }^{1,2}$, Tayou Tagny Claude ${ }^{3,4}$ \\ ${ }^{1}$ Internal Medicine Department, Faculty of Medicine and Pharmaceutical Sciences, University of Douala, Douala, Cameroon \\ ${ }^{2}$ Douala Obstetric and Pediatric Gynecological Hospital, Douala, Cameroon \\ ${ }^{3}$ Yaoundé Hospital and University Center, Yaoundé I, Cameroon \\ ${ }^{4}$ Faculty of Medicine and Biomedical Sciences, University of Yaoundé I, Yaoundé I, Cameroon
}

Email address:

noahnoahd@yahoo.fr (N. N. Dominique)

${ }^{*}$ Corresponding author

\section{To cite this article:}

Noah Noah Dominique, Eloumou Servais Albert Fiacre, Nsenga Djapa Guy Roger, Ze Meka Louis Philippe, Tayou Tagny Claude. Seroprevalence of Chronic Viral Hepatitis B in School Children Aged Less Than 10 Years in the Region of Southern Cameroon. International Journal of Infectious Diseases and Therapy. Vol. 5, No. 3, 2020, pp. 88-91. doi: 10.11648/j.ijidt.20200503.19

Received: May 5, 2020; Accepted: June 19, 2020; Published: September 3, 2020

\begin{abstract}
Introduction: Chronic viral hepatitis remain a public health problem worldwide. Being the seventh leading cause of the deaths, it accounts for 1.4 million deaths annually, with $47 \%$ related to hepatitis B and $48 \%$ to hepatitis $\mathrm{C}$. In Cameroon, screening for hepatitis B surface antigen $(\mathrm{HBsAg})$ is mandatory by the sixth month of pregnancy. This study aimed at evaluating the carriage rate of $\mathrm{HBsAg}$ among pupils in the south region, 10 years after the introduction of the pentavalent vaccine in the expanded immunization programme. Material and methods: This study was conducted in schools in Ebolowa (and its neighborhoods), south of Cameroon, during the five months period from November 1st 2015 to March 17th 2016. Eight schools were randomly selected. All children less than 10 years old were enrolled in our study. Children not meeting our selection criteria, or whose data forms were appropriately filled were excluded. Sampling was done by a laboratory technician of the Ebolowa regional hospital and transferred to the laboratory of the Yaounde University Teaching Hospital for analysis. Data was analyzed using the Epi info software. Results: A total of 471 pupils met our selection criteria with a male to female ration of 0.94 (243 females against 228 males). Five children were HBsAg positive, giving an overall prevalence of $1.06 \%$. Among the 471 pupils, only 166 were appropriately vaccinated as per the extended immunization programme, yielding $35.24 \%$ coverage. Conclusion: Despite the low immunization coverage rate, there is a positive impact on the prevalence of hepatitis B among children. Everything being equal, improving the immunization coverage as per the EPI will certainly yield lower rates of infection among children, and thus in the long run, within the general population.
\end{abstract}

Keywords: Carriage Rate, Hepatitis B, Infants, Vaccination, Ebolowa

\section{Introduction}

Chronic viral hepatitis remain a public health problem worldwide. Being the seventh leading cause of the deaths, it accounts for 1.4 million deaths annually, with $47 \%$ related to hepatitis B and $48 \%$ to hepatitis C. It was estimated that only 9\% (21.33 million) of all chronic infections are diagnosed, with only $8 \%$ of them ( 1.7 million) being on treatment [1].
As a result, the world health organization (WHO) set up a plan to fight these infections having as goal the screening of $90 \%$ of infected people, and treating $80 \%$ of them [1]. Mother-to-child transmission of hepatitis B remain a major route of the infection. Serovaccination of the newborn is paramount to prevention [1]. In 2013, the WHO Regional Committee aimed to reduce chronic hepatitis B (HB) infection to less than $1 \%$ among children aged 5 years and older by 2017 [2]. 
In Cameroon, prenatal screening for hepatitis B surface antigen (HBsAg) is mandatory at the sixth month of pregnancy [3]. When the result is positive, the newborn receives at birth at two separate sites a dose of the hepatitis $B$ vaccine and anti-hepatitis B surface immunoglobulin, both of which are given intramuscularly (IM) [3]. Implementing this policy remains challenging in semi-urban and rural environments as the monovalent vaccine and the anti-HBs immunoglobulin are difficultly available, accessible and affordable. In such settings, the pentavalent vaccine, introduced in the expanded immunization programme (EPI) in 2005 , remain the only option.

This study aimed at evaluating the carriage rate of $\mathrm{HBsAg}$ among pupils in the south region, 10 years after the introduction of the pentavalent vaccine in the expanded immunization programme.

\section{Material and Methods}

It was a cross sectional study which was carried out during a 5 months period (from November $1^{\text {st }} 2015$ to the $17^{\text {th }}$ of March 2016 in Ebolowa (headquarter of the South region). Eight schools were randomly selected, 4 in urban and 4 in rural environments. Our target population was children less than 10 years old, that is born after the introduction of the pentavalent vaccine in the EPI. Inclusion criteria were: aged less than 10 years old, being a pupil in one of the selected schools, having an informed consent signed by the parent or tutor. All children not meeting our selection criteria or those who turned out with inappropriately filled data entry forms were excluded from our study. We carried out a consecutive sampling.

We studied the following variables: demographic variables (gender, age, housing site, class), risk factors (past history of blood transfusion, scarifications, surgery and sexual abuse) both in the mother and the child, mother's HBsAg status and the child's immunization status.

A pre-established data entry form was sent to parents both for filling and give their informed written consent. Sampling was done by a staff of the Ebolowa regional hospital following all necessary aseptic rules. It was done using dry sterile tubes which were beforehand labelled. Samples were aliquoted before being transferred in a cool bag (between $2^{\circ} \mathrm{C}$ and $6^{\circ} \mathrm{C}$ ) the same day to the hematology laboratory of the Yaounde teaching hospital for analysis. A rapid test (Dia Spot HBsAg, France) was done on all the samples, and those which tested positive underwent a confirmatory test using ELISA assay (Murex HBsAg, France). The results were sent in sealed envelopes to parents by the gastroenterologist of the Yaounde central hospital. Participants who tested negative and not yet vaccinated were encouraged to do so.

Statistical analysis was done using the version 7 of the Epi info software. To compare two quantitative variables, we used the Khi -2 test. The Fischer's exact test was used for sample sizes less than 5, with a p-value less than 0.05 considered significant.

Ethical clearance was obtained from the ethical committee University of Douala. The study was approved by the management of the various schools selected for our study.

\section{Results}

A total of 471 children were enrolled, 243 (52\%) being girls and $228(48 \%)$ boys giving a male to female ratio of 0.94 .

When considering the site of sampling, $227(48 \%)$ was done in schools in rural environments, while 244 (52\%) were in urban environments.

Out of the 471 children enrolled, only 5 were HBsAg positive, giving an overall prevalence of $1.06 \%$. Zhen looking at the prevalence in the various environments, the prevalence was $1.64 \%$ in urban schools $(4 / 244)$ while it was $0.44 \%$ in rural schools $(1 / 227)$.

All infected children were boys mostly aged between 5 and 7 years old.

Only 166 out of the 471 children were appropriately vaccinated as per the expanded immunization program, yielding a vaccination coverage of $35.24 \%$.

Table 1 shows the HBsAg carriage state with respect to infection risk factors and vaccination coverage.

Table 1. HBsAg carriage with respect to risk factors in children.

\begin{tabular}{|c|c|c|c|c|c|}
\hline \multirow{2}{*}{ Risk factors } & & \multicolumn{2}{|l|}{ HBsAg } & \multirow{2}{*}{ Total } & \multirow{2}{*}{ p-value } \\
\hline & & Positive (\%) (n=5) & Négative (\%) $(n=466)$ & & \\
\hline \multirow{2}{*}{ Scarification } & yes & $1(1.82)$ & $54(98.18)$ & 55 & \multirow{2}{*}{0.46} \\
\hline & no & $4(0.96)$ & $412(99.04)$ & 416 & \\
\hline \multirow{2}{*}{ Blood transfusion } & yes & $0(0)$ & $21(100)$ & 21 & \multirow{2}{*}{0.80} \\
\hline & no & $5(1.11)$ & 445 (98.19) & 450 & \\
\hline \multirow{2}{*}{ Surgery } & yes & $0(0)$ & $15(100)$ & 15 & \multirow{2}{*}{0.85} \\
\hline & no & $5(1.09)$ & $451(98.91)$ & 456 & \\
\hline \multirow{2}{*}{ Sexual abuse } & yes & $0(0)$ & $2(100)$ & 2 & \multirow{2}{*}{0.98} \\
\hline & no & $5(1.06)$ & 464 (98.94) & 469 & \\
\hline \multirow{3}{*}{ Vaccination status (EPI) } & vaccinated & $1(0.60)$ & $165(99.40)$ & 166 & \multirow{3}{*}{0.65} \\
\hline & unknown & $2(1.04)$ & $190(98.96)$ & 192 & \\
\hline & Not vaccinated & $2(1.77)$ & $111(98.23)$ & 113 & \\
\hline
\end{tabular}

Table 2 summarizes the various mother's risk factors looked for in relation to her HBsAg, namely blood transfusion, number of sex partners (with or without protected sex), presence of STDs, tatooing, contacts with 
hepatitis B infected people.

Table 2. Distribution of mothers' HBsAg carriage with respect to her past history.

\begin{tabular}{|c|c|c|c|c|c|}
\hline \multirow{2}{*}{ Mother's past history } & & \multicolumn{2}{|c|}{ Mother's HBsAg carriage } & \multirow{2}{*}{ Total } & \multirow{2}{*}{ p-value } \\
\hline & & Yes $(\%)(n=5)$ & No $(\%)(n=466)$ & & \\
\hline \multirow{2}{*}{ Blood transfusion } & Yes & $0(0)$ & $29(100)$ & 29 & \multirow{2}{*}{0.73} \\
\hline & No & $5(1.13)$ & $437(98.814)$ & 442 & \\
\hline \multirow{6}{*}{ Number of sex partners } & 0 & $1(5.55)$ & $17(94.45)$ & 18 & \multirow{6}{*}{0.27} \\
\hline & 1 & $3(0.72)$ & $413(99.28)$ & 416 & \\
\hline & 2 & $1(4.35)$ & $22(95.65)$ & 23 & \\
\hline & 3 & $0(0)$ & $8(100)$ & 8 & \\
\hline & 4 & $0(0)$ & $3(100)$ & 3 & \\
\hline & 5 & $0(0)$ & $3(100)$ & 3 & \\
\hline \multirow{2}{*}{ STDs } & Yes & $2(4)$ & $48(96)$ & 50 & \multirow{2}{*}{0.09} \\
\hline & Non & $3(0.71)$ & $418(99.28)$ & 421 & \\
\hline \multirow{4}{*}{ Protected sex } & Never & $1(0.48)$ & $209(99.52)$ & 210 & \multirow{4}{*}{0.54} \\
\hline & Rarely & $3(1.86)$ & $158(98.14)$ & 161 & \\
\hline & Most often & $0(0)$ & $33(100)$ & 33 & \\
\hline & Always & $1(1.52)$ & $65(98.48)$ & 66 & \\
\hline \multirow{2}{*}{ Surgery } & Yes & $1(1.33)$ & $74(98.64)$ & 75 & \multirow{2}{*}{0.58} \\
\hline & No & $4(1.01)$ & $392(98.99)$ & 396 & \\
\hline \multirow{2}{*}{ Tatooing } & Yes & $0(0)$ & $11(100)$ & 11 & \multirow{2}{*}{0.89} \\
\hline & No & $5(1.09)$ & $455(98.91)$ & 460 & \\
\hline \multirow{2}{*}{$\begin{array}{l}\text { Contact with infected } \\
\text { person }\end{array}$} & Yes & $2(3.77)$ & $51(96.23)$ & 53 & \multirow{2}{*}{0.10} \\
\hline & No & $3(0.72)$ & $414(99.28)$ & 417 & \\
\hline Infected person & Mother & 0 & 6 & 6 & 1 \\
\hline
\end{tabular}

\section{Discussion}

Our sample size was 471, a value close to that of PrabdialSing et al in a study carried out in South Africa and published in 2019, evaluating the prevalence of HBsAg among children less than 15 years old [4]. Our size is however less than that of Fortuin et al in Gambia, while evaluating the expanded programme of immunization in 1993 [5]. The sex ratio of 0.94 in favour of girls not only is in line with the tendency in the general population, but also portrays the progressive social trend of having the girl child educated.

According to data published by The World fact book, children aged between 0 and 14 years old represent $42.34 \%$ of the population of Cameroon, with however a male to female ratio of 1.02 [6], which is not what we found in our study.

The prevalence of HBsAg in our population was $1+/-$ $0.10 \%$. It is close to $1 \%$ found by Shao Xiaoping et al in China in 2013 [7], and the $1.11 \%$ obtained by Ximenes et al in Brazil in 2015 among children aged between 1 and 14 years old, 20 years after the introduction of the hepatitis B vaccine in the expended programme of immunization [8]. These results reflecting the efficacy of the introduction of the hepatitis $\mathrm{B}$ vaccine in the expanded program of immunization has equally being described in a report published by Global hepatitis in 2017 according to which vaccination led to a drop in the prevalence of hepatitis $B$ from $4.7 \%$ to $1.3 \%$ among children less than 5 years old [1]

Our finding were however greater than those described by Magoni et al. in the Grand Bassam health district in Côte d'Ivoire and by Yen et al. among children and teenagers in a study in Taiwan, (15 years after the introduction of the vaccine in the EPI who both got $0.7 \%[9,10]$. More so, AlFaleh et al. in 1999 among Saudi children had a prevalence of $0.31 \%, 8$ years after the introduction of the vaccine, while Iman et al. In 2015 in Egypt found $0.11 \%, 10$ years after the introduction of the vaccine $[11,12]$. This discrepancy can be accounted for by the fact that the vaccination coverage in the South, where our study was carried out was $35.24 \%$. As a matter of facts, it has been established that there is a positive correlation between the efficacy of vaccination and vaccination coverage [1].

All HBsAg carriers were boys. Many studies have shown this male predominance. In 2003, a survey carried out by the Institut de Veille Sanitaire in France showed this male predominance in the prevalence of hepatitis B irrespective of the age group [13]. Eloumou et al. in 2014 equally showed this trend in a population of students of the faculty of medicine and of pharmaceutical sciences if the Douala University. The prevalence among men was $3.6 \%$ while it was $2 \%$ among women [14].

Taking into account the vaccination status, the rate of children appropriately vaccinated (having received the 3 doses) was $35.24 \%$, with 4 out of the $5 \mathrm{HBsAg}$ positive children not being appropriately vaccinated. The hepatitis $B$ vaccine is the major means of preventing infection. The World Health Organisation (WHO) recommends the administration of the vaccine as soon as possible after birth, preferably within the 24 hours following delivery. Systematic vaccination of infants against hepatitis B has gained grounds at global level, with a vaccination coverage (ascertained by a third dose) estimated at $84 \%$ in 2017. The low prevalence of chronic hepatitis B infections in children less than 5 years old, estimated at $1.3 \%$ in 2015 , can be accounted for by generalized uptake of the 
vaccine [1].

\section{Conclusion}

Despite the low vaccination coverage, it certainly has an impact on the prevalence of hepatitis among children. Everything being equal, improving the immunization coverage as per the EPI will certainly yield lower rates of infection among children, and thus in the long run, within the general population.

\section{References}

[1] https://www.who.int/hepatitis/publications/global-hepatitisreport2017-executive-summary/fr/ (7 janvier 2020).

[2] World Health Organization Regional Office for the Western Pacific Regional Action Plan for Viral Hepatitis in the Western Pacific 2016-2020: a priority action plan for awareness, surveillance, prevention and treatment of viral hepatitis in the Western Pacific Region In: World Health Organization. ed. Manila: WHO; 2016.

[3] Sogni P. Hepatites virales et grossesse. Hepato Gastro 2013; 20: $\quad 595-600$. doi: $10.1684 / \mathrm{hpg} .2013 .0923$ sciences biomédicales; 2006.

[4] Prabdial-Sing N, Makhathini L, Smit SB, Manamela MJ, Motaze NV, Cohen C et al. Hepatitis B sero-prevalence in children under 15 years of age in South Africa using residual samples from community-based febrile rash surveillance. PLoS One. 2019 May 31; 14 (5): e0217415. doi: 10.1371/journal.pone.0217415. eCollection 2019.

[5] Fortuin M, Chotard J, Jack AD, Maine NP, Mendy M, Hall AJ, Inskip HM, George MO, Whittle HC. Efficacy of hepatitis B vaccine in the Gambian expanded programme on immunisation. Lancet; 1993 May 1; 341 (8853): 1129-31.
[6] https://www.cia.gov/library/publications/the-worldfactbook/geos/cm.html (18 février 2020).

[7] Shao Xiaoping, Wu Chenggang, Wangfu Zhen, Liang Jian Xie Xin Zhu Qi Liu Jun Hu Pei Quan Qiu. 2013 County, province of three Guangdong children aged 1 to 14 investigations HBV serological analysis. Journal of Preventive Medicine, 2015, 49 (09): 777-781.

[8] Ximenes RA, Figueiredo GM, Cardoso MR, Stein AT, Moreira RC, Coral G, et al. Enquête multicentrique basée sur l'infection de l'hépatite $B$ et facteurs de risque dans les régions du Nord, du Sud, du Sud - Est et du Brésil, 10-20 ans après le début de la vaccination. Am J Trop Med Hyg 2015 décembre; 93 (6): 1341-8.

[9] Yen HN, et al. Hepatitis B Infection by the virus in children and adolescents in a hyperendemic area: 15 years after mass hepatitis B immunization. Ann Intern Med. 2001; 135 (9): 796-800.

[10] Magoni M, Ekra KD, Aka LN, Sita KS, Kanga K. Effectiveness of vaccination against hepatitis B in Côte d'Ivoire: the case of the health district Grand Bassam. Ann Trop Med Parasitol 2009 Sep; 103 (6): 519-27.

[11] Iman J, et al. Efficacy of hepatitis B vaccination in Egypt program: national project Multicenter. Monde J Hepatol. Monde J Hepatol. 8 October 2015; 7 (22): 2418-2426. 53.

[12] Al-Faleh FZ, Al-Jeffri M, Ramia S, Al-Rashed. Seroepidemiology of hepatitis virus infection B in Saudi children 8 years after a vaccination program against hepatitis B of mass. J Infect. 1999 May; 38 (3): 167-70.

[13] http://www.invs.sante.fr/publications/2005/analyse_descriptiv e_140205/rapport_analyse_descriptive.pdf (09 mars 2020).

[14] Eloumou Bagnaka SAF, Noah Noah D, Ngaba GP, Luma Namme H, Adiogo D et al. Statut Vaccinal Contre le Virus de l'Hépatite Virale B et Portage de l'Antigène Hbs chez les Etudiants en Médecine et en Pharmacie de l'Université de Douala au Cameroun. Health Sci. Dis: Vol 15 (2) April-MayJune 2014: 2-5. 